\title{
Correction to: Comparison of rodent community between natural and modified habitats in Kafta-Sheraro National Park and its adjoining villages, Ethiopia: implication for conservation
}

\author{
Alembrhan Assefa ${ }^{1}$ and Srinivasulu Chelmala ${ }^{2^{*}}$
}

Correction to: JoBAZ (2019) 80:59

https://doi.org/10.1186/s41936-019-0128-9

In the original version of this article (Assefa \& Chelmala, 2019), published on 5 September 2019, there was 1 incorrect author name.

The incorrect author name was published as:

Alemrhan Assefa

The correct author name is:

Alembrhan Assefa

The original publication of this article has been corrected.

\section{Author details}

'Wildlife Biology and Taxonomy Lab, Department of Zoology, University College of Science, Osmania University, Hyderabad, Telangana 500007, India. ${ }^{2}$ Natural History Museum \& Wildlife Biology and Taxonomy Lab, Department of Zoology, University College of Science, Osmania University, Hyderabad, Telangana 500007, India.

Published online: 01 November 2019

\section{Reference}

Assefa, A., \& Chelmala, S. (2019). Comparison of rodent community between natural and modified habitats in Kafta-Sheraro National Park and its adjoining villages, Ethiopia: implication for conservation. JOBAZ, 80, 59. https://doi.org/ 10.1186/s41936-019-0128-9

\footnotetext{
* Correspondence: chelmalasrinivasulu@gmail.com

The original article can be found online at https://doi.org/10.1186/s41936019-0128-9

${ }^{2}$ Natural History Museum \& Wildlife Biology and Taxonomy Lab, Department of Zoology, University College of Science, Osmania University, Hyderabad, Telangana 500007, India

Full list of author information is available at the end of the article
} 